\title{
POTRET DAKWAH DALAM KEGIATAN KKN STIBA MAKASSAR DI DESA BARUGA KABUPATEN MAROS
}

\author{
Mukran H Usman \\ Sekolah Tinggi Ilmu Islam dan Bahasa Arab (STIBA) Makassar \\ Mukran@stiba.ac.id
}

Keywords :

Dakwah, Community

Program, Baruga.

\begin{abstract}
Baruga Village is a religious community and still adheres to life character of mutual cooperation which is integrated with the customs that characterize the life of the Baruga Village community. The philosophy of life is based on the principle of achieving prosperity with a high work ethic escorted by a spirit of unity and togetherness, even if the people of Baruga Village are overseas. STIBA Makassar Community Service Program (KKN) III was to practice the higher education tri dharma as a form of community service. The method of community service implementation in Baruga Village was started by analyzing the needs of the community by using instruments that were made independently and SOAR analysis. This was useful for identifying problems and developing work program strategies. STIBA Makassar Community Service Program (KKN) III in Baruga Village was started with a Work Program Seminar (SPK), then Training on Taking Care of a Corpse (PPJ), Hospitality and Health Services (SAPK), Religious Children's Festival (FAS) and Islamic Signs (RRI). The result of this KKN is that it can be seen in terms of knowledge in the community experiencing the development in Islamic insight, especially in terms of proficiency in recognizing hijaiyah letters, makhraj and tajwid in reading the Koran. In terms of skills, it is especially seen from the side of community skills in taking care of a corpse. In terms of attitude, the community already has a high enthusiasm in learning and practicing Islamic knowledge.
\end{abstract}

Desa Baruga adalah masyarakat yang religius dan masih melekat
adanya karakter hidup bergotong royong yang berbaur dengan adat
istiadat yang mewarnai kehidupan masyarakat Desa Baruga.
Falsafah hidup pun demikian berprinsip mencapai kemakmuran
dengan etos kerja yang tinggi disertai dengan semangat persatuan
dan kebersamaan, meskipun warga Desa Baruga berada di
perantauan. Kuliah Kerja Nyata (KKN) STIBA Makassar angkatan
III adalah untuk mengamalkan tri dharma perguruan tinggi sebagai
wujud pengabdian kepada masyarakat. Metode pelaksanaan
pengabdian masyarakat di Desa Baruga ialah diawali dengan
melakukan analisis kebutuhan masyarakat dengan menggunakan
instrumen yang dibuat secara mandiri dan analisis SOAR. Hal itu
berguna untuk pengidentifikasian masalah dan strategi penyusunan
program kerja. Adapun proker mahasiswa KKN STIBA Makassar
angkatan III di Desa Baruga yaitu diawali dengan Seminar Program
Kerja (SPK), lalu Pelatihan Penyelenggaraan Jenazah (PPJ),
Silaturahmi Akbar dan Pelayanan Kesehatan (SAPK), Festival Anak
Saleh (FAS) dan Rambu-Rambu Islami (RRI). Adapun hasil dari

Kata kunci :

Dakwah, KKN, Baruga 
WAHATUL MUJTAMA': Jurnal Pengabdian Masyarakat

Vol. 1, No. 1 (2020) : Hal. 75-89

Website: https://journal.stiba.ac.id

KKN ini ialah dapat dilihat dari segi pengetahuan dalam masyarakat mengalami perkembangan wawasan keislaman, terutama dari sisi kemahiran mengenali huruf hijaiah, makraj dan tajwid dalam bacaan al-Qur'an. Dari segi keterampilan, terutama terlihat dari sisi kecakapan masyarakat dalam penyelenggaan jenazah. Dari segi sikap, masyarakat sudah memiliki antusiasme tinggi dalam mempelajari dan mengamalkan ilmu keislaman. 


\section{PENDAHULUAN}

Geografis Desa Baruga; Desa Baruga merupakan salah satu desa yang terletak di Kecamatan Bantimurung, Kabupaten Maros dengan luas wilayah 52,51 km yang terbagi atas 5 dusun yakni Dusun Kassi, Cambajawa, Batunpara, Samariga dan Balang. Batas wilayah Desa Baruga; sebelah timur berbatasan dengan Desa Tukamasea, sebelah utara berbatasan dengan Kabupaten Pangkep, sebelah barat berbatasan dengan Desa Salenrang, dan sebelah selatan berbatasan dengan Desa Mattoanging.

Kondisi iklim wilayah Desa Baruga; Desa baruga seperti pada umumnya desadesa yang lain di Kecamatan Bantimurung yakni mempunyai iklim kemarau, pancaroba dan penghujan. Hal tersebut mempunyai pengaruh langsung terhadap pola tanam yang ada di Desa Baruga beserta desa yang lain yang ada di Kecamatan Bantimurung. Berdasarkan data curah hujan selama lima tahun terakhir adalah tipe iklim tropis menurut Oldeman maka terdapat dua tipe yaitu: ${ }^{1}$

1. Tipe c. 2 adalah bulan basah 2-5 bulan dan bulan kering 2-3 bulan.

2. Tipe c.3 adalah bulan basah 5-6 bulan dan bulan kering 3-5 bulan.

Bulan basah umumnya jatuh pada bulan November sapai bulan April, sedangkan bulan kering jatuh pada bulan Mei sampai Oktober. Sedangkan temperatur udara berkisar antara 25 sampai 35 derajat celcius, terendah pada musin hujan dan tertinggi pada musim kemarau. Karakteristik tanah; adapun karakteristik tanah di Desa Baruga termasuk jenis Tanah Alluvial dengna $\mathrm{Ph}$ tanah lahan kering 5,8-7 dan lahan sawah 5,5-6.

Demografis Desa Baruga: Desa Baruga merupakan salah satu desa di wilayah Kecamatan Bantimurung yang memiliki jumlah penduduk sebanyak 4490 jiwa, yang terdiri dari laki-laki sebanyak 2280 jiwa dan perempuan sebanyak 2210 jiwa dari jumlah kepala keluarga sebanyak 1111 KK. Adapun keyakinan yang dianut oleh seluruh masyarakat di Desa Baruga adalah agama Islam. Berikut penyajian data ihwal sebaran penduduk Desa Baruga yang diuraikan sebagai berikut:

Tabel 1.1. Sebaran Penduduk Desa Baruga.

\begin{tabular}{llccc}
\hline \multirow{2}{*}{ No } & \multirow{2}{*}{ Dusun } & \multicolumn{2}{c}{ Jenis Kelamin } & \multirow{2}{*}{ Total } \\
\cline { 2 - 4 } & & Pria & Wanita & \\
\hline 1 & Kassi & 155 & 168 & 323 \\
\hline 2 & Cambajawa & 458 & 439 & 897 \\
\hline 3 & Batunapara & 990 & 912 & 1.902 \\
\hline 4 & Samariga & 322 & 308 & 630 \\
\hline 5 & Balang & 355 & 384 & 738 \\
\hline
\end{tabular}

Sumber: Buku perkembangan penduduk Desa Baruga tahun 2018.

${ }^{1}$ Sari, N., Indarto, S. W., \& Wahyuningsih, S. Klasifikasi Sub Tipe Iklim Oldeman: Studi Kasus di Wilayah UPT. (2014): h. 3-4. 
Potensi Lokal Desa Baruga: Mata pencaharian masyarakat Desa Baruga didominasi oleh aktivitas pertanian. Hal tersebut dapat dilihat bahwa sebagian besar wilayah desa diperuntukkan untuk lahan pertanian. Di antara hasil pertanian yang ada di Desa Baruga yakni yang paling besar menyumbang pendapatan desa adalah hasil pertanaman padi dan palawija. Hasil pertanian lain yang dijadikan sebagai komoditi perdagangan adalah pisang, jagung, sereh, lengkuas, kedelai, gabah serta berbagai jenis hasil tanaman sayur-sayuran. Selain hasil bumi, mata penaharian masyarakat Desa Baruga mencakup hasil peternakan berupa sapi, kambing, ayam, dan itik. Adapun Sarana prasarana desa yang ada sebagai penopang ekonomi masyarakat yaitu sarana transportasi; seperti jalanan Cor beton (sekitar $13 \mathrm{~km}$ ), jalan tanah $2 \mathrm{~km}$ serta saluran irigasi sepanjang $5 \mathrm{~km}$, jembatan Tani, kemudian ditambah dengan aliran sungai sepanjang $10 \mathrm{~km}$.

Selain bertani, sebagian masyarakat Desa Baruga bekerja di PT. Semen Bosowa. Dengan adanya perusahaan ini, masyarakat lebih mudah mendapatkan pekerjaan yang tidak jauh dari kampung halamannya dan juga bisa lebih meningkatkan perekonomian keluarga tanpa bergantung pada pertanian saja yang terkadang hasilnya tidak menentu (fluktuatif). Namun begitu, sebagian masyarakat Desa Baruga ada juga yang merantau ke luar pulau seperti Papua. Dan beberapa dari perantau tersebut yang usahanya berhasil di daerah perantauannya, mengajak keluarga dan kerabatnya bergabung dan ikut merantau bersama mereka.

Dari sisi agama dan budaya, ciri khas masyarakat Desa Baruga adalah masyarakat yang religius dan masih melekat adanya rasa hidup gotong-royong yang berbaur dengan adat istiadat yang mewarnai kehidupan masyarakat Desa Baruga. Hal tersebut dapat dilihat bahwa sebagian besar masyarakat Desa Baruga memeluk agama Islam. Sementara komunitas yang sadar akan sunah bisa ditemukan di Perumahan Bosowa (sebagian besar bukan penduduk asli, melainkan para pendatang) dengan beberapa kajian rutinnya. Disamping itu, ada sebagian kecil pemeluk Kristen. Setiap dusun memiliki tempat ibadah berupa masjid yang dibangun dengan swadaya masyarakat serta ditambah dengan dana ADD pemerintah Desa Baruga.

Kebiasaan masyarakat yang sudah turun temurun atau adat istiadat masyarakat masih sangat melekat dalam kehidupan bermasyarakat dan itu menjadi salah saatu motivasi kerja bagi sebagian masyarakat, khususnya para petani di Desa Baruga. Tradisi lokal masih dipelihara dan dijadikan sebagai wadah untuk mempererat persatuan dan kebersamaan dalam kehidupan bermasyarakat di Desa Baruga. Baik yang masih menetap atau tinggal di dalam desa maupun di daerah perantauan, dan adalah tradisi lokal tersebut juga dapat menumbuhkan etos kerja bagi masyarakat.

Dari sisi kesehatan, dalam memenuhi tingkat kebutuhan masyarakat akan pelayanan kesehatan, maka Pemerintah Kabupaten Maros telah membangun fasilitas pelayanan kesehatan di Desa Baruga yaitu Puskesmas Pembantu (PUSTU). Pustu ini sangat berfungsi dengan baik dalam melayani masyarakat seperti pemberian layanan pemeriksaan kesehatan, pemberian obat oleh tenaga medis yang bertugas kepada pasien, 
serta kadang dijadikan sebagai tempat rawat inap bagi pasien yang tidak terlalu parah penyakitnya dan butuh perawatan yang intensif, alih-alih juga digunakan untuk pemeriksaan bagi para lansia. Selain PUSTU di Desa Baruga, juga terdapat Pos Pelayanan Terpadu (POSYANDU) yang telah dibangun oleh Pemerintah Desa Baruga melalui anggaran dana ADD. Fasilitas ini digunakan sebagai tempat pelayanan kesehatan masyarakat, seperti penimbangan balita, vaksinasi, serta pemeriksaan para manula. Terdapat tiga Posyandu telah dilengkapi dengan kamar periksa di Desa Baruga.

Berdasarkan profil Desa Baruga di atas, maka ditetapkan tujuan dari pelaksanaan pengabdian kepada masyarakat (PkM) yang hendak dilakukan oleh pihak Sekolah Tinggi Ilmu Islam dan Bahasa Arab (STIBA) Makassar bekerja sama dengan Pemerintah Kec. Bantimurung, khusunya Desa Alatengae dalam bentuk KKN mahasiswa STIBA Makassar angkatan III. Paparan tujuan disajikan sebagai berikut:

1. Menumbuhkan kesadaran sosial mahasiswa dalam berdakwah berbasis ilmu pengetahuan Islam yang telah diperoleh selama di STIBA Makassar.

2. Mengembangkan kompetensi dakwah lapangan mahasiswa STIBA Makassar.

3. Mengamalkan tri dharma perguruan tinggi bagi Dosen Pembimbing Lapangan (DPL) pada pilar pengabdian kepada masyarakat.

4. Mengembangkan eksistensi STIBA Makassar sebagai perguruan tinggi berbasis pengkaderan ulama dan organisatoris yang bermanfaat kepada masyarakat.

Sebelum melangkah ke bab pembahasan, maka diuraikan pula metode pelaksanaan KKN ini yaitu dimulai dengan melakukan survei lapangan dengan menggunakan instrumen buatan mandiri lalu kemudian dilakukan analisis SOAR. Tujuannya adalah untuk mengidentifikasi problem masyarakat, memetakan masalah, kebutuhan uluran dakwah, dan menyusun strategi penyusunan program KKN yang meliputi bidang pendidikan, sosial, dan kesehatan. Berdasarkan survei lapangan masyarakat Desa Baruga melalui lensa analisis SOAR. sederhananya disajikan berikut ini:

1. Strenght: masyarakat Desa Baruga berkarakter religius, etos kerja tinggi, dan soliditas yang baik. Mahasiswa STIBA Makassar telah dibekali pemahaman agama yang baik, memiliki keterampilan bekam dan rukyah, serta terlatih dalam mengajarkan metode tilawati dan metode dirosa untuk pengajaran al-Qur'an.

2. Oppurtunities: Dukungan penuh aparat pemerintah Desa Baruga, kepala sekolah, warga Perumahan Bosowa, dan imam-imam dusun berupa fasilitas dan dukungan moril.

3. Aspiration: Desa Baruga menjadi desa binaan, masyarakat lebih mengenal lebih lanjut terhadap pengobatan Nabi (thibbun nabawi) berupa bekam dan rukyah syar'i, santri-santriwati dapat membaca al-Qur'an dengan baik dan benar.

4. Result: terwujudnya Desa Baruga sebagai desa yang bernuansa Islami, masyarakat mengenal dan mempraktekkan pengobatan syar'i dalam kehidupan keseharian, 
santri-santriwati membaca al-Qur'an dengan baik dengan benar serta mengajarkannya kembali kepada generasi selanjutnya.

Dengan demikian, bentuk PkM berwujud KKN dipetakan berupa programprogram dakwah KKN yaitu diawali dengan Seminar Program Kerja (SPK), perhelatan umum berupa Pelatihan Penyelenggaraan Jenazah (PPJ), Silaturahmi Akbar dan Pelayanan Kesehatan (SAPK), Festival Anak Saleh (FAS), dan Rambu-Rambu Islami (RRI). Adapun pengajaran TK/TPA, sifatnnya rutin dilaksanakan. Namun, tidak dipaparkan dalam bab pembahasan karena sudah terwakili oleh FAS.

Sejumlah bentuk PkM terdahulu dan relevan dengan Pengabdian Masyarakat berwujud KKN angkatan STIBA Makassar disajikan selanjutnya. Tujuannya bersifat untuk menarasikan secara singkat state of art alih-alih menyajikan kesamaan dan peluang kebaharuan hasil dalam pelaksanaan program PkM (KKN) ini.

1. PkM yang dilakukan oleh Lingga ihwal pembinaan kesadaran masyarakat terhadap lingkungan hidup, menunjukkan bahwa hasil dan kendala dari program KKN Tematik Citarum Harum, yaitu masyarakat merasakan manfaat serta wawasan baru tentang lingkungan hidup terutama dalam mengatasi masalah lingkungan hidup salah satunya sampah. Kendala yang dihadapi dalam menumbuhkan kesadaran masyarakat terhadap lingkungan hidup tidak cukup hanya dengan empat puluh hari, dalam pelaksanaannya membutuhkan waktu yang panjang serta pengawasan dari pihak terkait. ${ }^{2}$

2. PkM yang dilakukan oleh Asriati, dkk., ihwal peningkatan kompetensi masyarakat kecil menunjukkan keberhasilan dalam membekali pengetahuan, sikap, dan keterampilan usaha-usaha industri yang dilakukan oleh kelompok warga belajar di PKBM. Dalam upaya pelaksanaan kegiatan program KKN-PPM terlebih dahulu dilaksanakan survey lokasi, pendekatan dengan beberapa kelompok belajar di PKBM dan melakukan sosialisasi program. ${ }^{3}$

3. PkM yang dilakukan oleh Sulastri ihwal pemberdayaan masyarakat dan pengembangan civic participation mahasiswa menunjukkan hasil pelaksanaan program KKN tematik yang menghasilkan produk, penguatan dan pendampingan Posdaya, serta perubahan sikap, pengetahuan dan keterampilan yang dirasakan oleh mahasiswa dan masyarakat. ${ }^{4}$

${ }^{2}$ Lingga, Z. A. Program KKN Tematik Citarum Harum Mahasiswa UPI 2018 Dan Pembinaan Kesadaran Masyarakat Terhadap Lingkungan Hidup: Studi Deskriptif di Desa Cangkuang Kulon Kabupaten Bandung (Doctoral Dissertation, Universitas Pendidikan Indonesia, 2019).

${ }^{3}$ Asriati, N., \& Indrawati, U. S. Y. V. Pendampingan Program Usaha Mikro Kecil Menengah Berbasis Pusat Kegiatan Belajar Masyarakat (Pkbm) Melalui Kkn-Ppm Daerah Pemekaran Kubu Raya Kalimantan Barat. Jurnal Dinamika Pengabdian (JDP), Vol.5, No.1, (2019): h.12-18.

${ }^{4}$ Ayu Sulastri. Peran Program Kuliah Kerja Nyata Tematik Pos Pemberdayaan Keluarga (Posdaya) Dalam Pengembangan Civic PARTICIPATION MAHASISWA: Studi Deskriptif pada Pelaksanaan KKN Tematik Posdaya UPI di Desa Gunajaya Kecamatan Manonjaya (Doctoral dissertation, Universitas Pendidikan Indonesia, 2017) 
4. PkM yang dilakukan oleh Aslam dkk., ihwal pendirian perpustakaan mini dan pengadaan buku-buku Islami di Dusun Bengkak menunjukkan keberhasilan menghasilkan mendirikan "Taman Baca Bengkak" dalam mana terdapat 52 buku dan beberapa meja kecil untuk membaca serta peralatan alat tulis lainnya. Selain itu, Aslam dkk., melalui KKN, telah berhasil mengadakan bimbingan belajar bagi PAUD-SMP yang waktunya bertepatan sesudah TPA. ${ }^{5}$

5. PkM yang dilakukan oleh Saharuddin menunjukkan hasil pencapaian dari kegiatan KKN-PPM-nya berupa terciptanya lingkungan yang bersih dan nyaman, tersedianya guru pengajar sesuai kurikulum TPA di setiap musala, tumbuhnya jiwa kewirausahaan ibu rumah tangga, dan tersedianya obat-obat alami dari tanaman TOGA (Tanaman Obat Keluarga). ${ }^{6}$

Berdasarkan hasil-hasil pengabdian kepada masyarakat $(\mathrm{PkM})$ di atas, maka didapati memiliki kesamaan dari segi wujud PkM yang terealisasi dalam bentuk KKN, demikian halnya dengan KKN angkatan III STIBA Mahassar. Kesamaan itu pula tampak dari perencanaan dan penyusunan program yang berorientasi pada upaya pengubahan dan peningkatan kompetensi masyarakat, baik dari sisi pengetahuan, keterampilan dan sikap. Perbedaan atau hal yang belum ditemui dari hasil PkM di atas yakni program yang disusun belum didasari oleh metode analisis kebutuhan masyarakat yang mumpuni atau populer semisal analisis SWOT ataupun SOAR, dan lain sebagainya.

Pada PkM berwujud KKN STIBA Makassar angkatan III di Desa Baruga, maka diupayakan strategi penyusunan program kerja berangkat dari survei lapangan dengan dan analisis kebutuhan masyarakat dengan metode SOAR. Selain itu, dalam KKN ini akan dipaparkan mulai dari langkah-langkah pelaksanaan program kerja, pengalaman menarik yang dijumpai, faktor pendukung, hasil kegiatan, dan keberlanjutan (follow up) kegiatan. Adapun program-program kerja dakwah melalui KKN juga diupayakan bersifat sustainable (berkelanjutan). Dengan demikian, kerjasama antara pihak STIBA Makassar dan Pemerintah Desa Baruga atau Kecamatan Bantimurung akan diikat melalui memorandum of understanding $(\mathrm{MoU})$.

\section{PEMBAHASAN}

Bentuk-bentuk program kerja KKN mahasiswa angkatan III STIBA Makassar di Desa Alatengae yaitu Seminar Program Kerja (SPK), perhelatan umum berupa Pelatihan Penyelenggaraan Jenazah (PPJ), Silaturahmi Akbar dan Pelayanan Kesehatan (SAPK),

\footnotetext{
${ }^{5}$ Aslam, K. Dkk. Penguatan Keimanan dan Pengetahuan Masyarakat Dusun Bengkak dalam Rangka Program berkelanjutan KKN 220 Melalui Mini Perpustakaan dan Pemberian Buku Bacaan Islami. Prosiding Konferensi Pengabdian Masyarakat, Vol.1, (2019): h.33-36.

${ }^{6}$ Saharuddin, S. Pengabdian KKN-PPM Desa Wonorejo Kecamatan Mangkutana Kabupaten Luwu Timur. RESONA: Jurnal Ilmiah Pengabdian Masyarakat, Vol.1, No.1, (2017)
} 
WAHATUL MUJTAMA': Jurnal Pengabdian Masyarakat

Vol. 1, No. 1 (2020) : Hal. 75-89

Website: https://journal.stiba.ac.id

Festival Anak Saleh (FAS), dan Rambu-Rambu Islami (RRI). Adapun pengajaran TK/TPA, sifatnnya rutin dilaksanakan dan paparannya terwakili oleh kegiatan FAS.

\section{Seminar Program Kerja (SPK)}

Salah satu proker mahasiswa KKN angkatan III STIBA Makassar adalah mengadakan seminar program kerja yang dilaksanakan setelah masa penjajakan telah dilakukan dengan melihat kegiatan yang lebih dibutuhkan oleh masyarakat setempat. Kegiatan ini dimaksudkan untuk mensosialisasikan program kerja selama masa KKN di Desa Baruga serta meminta kerjasama aparat desa dan warga secara umum. Menurut Mukit sosialisasi (seminar penyuluhan) bertujuan untuk meningkatkan respon, pengetahuan, dan kesadaran masyarakat terhadap suatu agenda kegiatan. ${ }^{7}$ Adapun kegiatan ini dilaksanakan pada Senin, 13 Januari 2020 pada pukul 14.00-15.00 di Kantor Desa Baruga. Langkah-langkah kegiatan SPK diawali dengan membuat konsep kegiatan, kemudian menyelesaikan administrasi kegiatan dan atau persuratan, selanjutnya melakukan sosialisasi, terakhir, melaksanakan kegiatan seminar program kerja.

Pengalaman menarik yang dijumpai adalah ditemukan peserta yang merupakan imam dusun meminta agar ada mahasiswa yang kultum di masjid dan tanpa harus dipersilakan lagi untuk berdiri dalam memberikan tausiah. Adapun faktor pendukung kegiatan SPK ini adalah fasilitasi yang diberikan oleh pihak aparat desa, dan warga merasa terbuka untuk menerima kehadiran mahasiswa KKN angkatan III STIBA Makassar. Demikian juga ditemukan kendala dalam SPK ini berupa kehadiran warga yang tidak maksimal, dan tindakan solutif untuk menutupi kekurangan tersebut adalah dengan memaksimalkan sosialisasi kegiatan ke masyarakat.

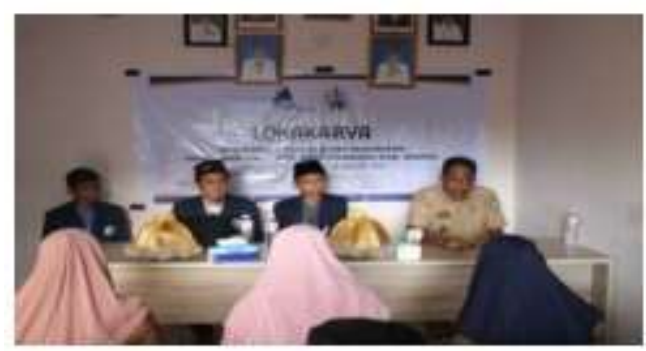

Gambar 1.1. Seminar Program Kerja

Hasil kegiatan menunjukkan bahwa gambaran masyarakat sebelum mengikuti seminar KKN STIBA Makassar adalah masyarakat tidak mengetahui keberadaan dan program kerja mahasiswa KKN angkatan III STIBA Makassar di Desa Baruga. Baru setelah kegaiatan SPK dilaksanakan, masyarakat telah mengetahui kedatangan dan juga

${ }^{7}$ Mukit, A. Peningkatan Kesadaran Masyarakat untuk Membayar Pajak Melalui Program Sosialisasi Perpajakan (Studi pada Program Kerja KKN Mahasiswa IAIN Jember di Dusun Gambiran Desa Mumbulsari). Prosiding Konferensi Pengabdian Masyarakat,Vol.1, (2019): h.201-204. 
maksud dan tujuan program kerja yang dicanangkan oleh mahasiswa. Adapun keberlanjutan (follow up) kegiatan seminar program kerja (SPK) KKN STIBA Makassar ialah dengan melaksanakan program kerja yang telah diagendakan selama masa KKN berlangsung, kisaran 45 hari masa pengabdian.

\section{Pelatihan Penyelenggaraan Jenazah (PPJ)}

Pelatihan penyelenggaraan jenazah merupakan salah satu program yang diagendakan sebagai bentuk pelatihan kepada masyarakat. Dalam penyelenggaraan jenazah, dimulai dari memberikan pemahaman tentang kematian hingga mensolati jenazah dengan benar yang sesuai dengan tuntunan syariat. Kegiatan ini dilaksanakan pada senin, 27 januari 2020 pada pukul 14.00-17.00 di Masjid Miftahussala Samariga.

Langkah-langkah kegiatan PPJ dimulai dengan membuat konsep kegiatan, kemudian menyelesaikan administrasi kegiatan (persuratan), dan melakukan sosialisasi, selanjutnya melaksanakan kegiatan. Pada saat kegiatan PPJ berlangsung, para peserta menerima materi hukum seputar kematian, kumudian peserta dipersilakan praktik penyelenggaraan jenazah yang dimulai dari menyiapkan peralatan jenazah hingga mensolatinnya.

Pengalaman menarik yang ditemukan adalah antusias masyarakat terhadap pelatihan penyelenggaraan jenazah (PPJ) yang dibuktikan dengan tanya jawab masyarakat terhadap tata cara penyelenggaraan jenazah kepada pemateri. Bahkan peserta sempat bersitegang disebabkan kain kafan yang disediakan oleh pemateri telah dijahit rapi sedangkan warga merasa itu adalah hal baru bagi mereka. Adapun faktor pendukung kegiatan PPJ adalah pengurus Masjid Miftahussala Samariga memberikan izin pemakaian masjid sebagai tempat kegiatan PPJ, sembari warga setempat sangat mengapresiasi atas diadakannya program kerja PPJ.

Kendala yang dijumpai pada pelaksanaan PPJ adalah kehadiran peserta kegiatan dan keterlambatan pemateri yang datang ke lokasi PPJ. Hal ini disebabkan oleh kurangya komunikasi yang baik antara pemateri dan panitia. Dengan demikian, belajar dari pengalaman mahasiswa KKN diharapkan memaksimalkan sosialisasi kegiatan dan menjalin komunikasi yang baik antar pemateri dan panitia jauh hari sebelum perhelatan PPJ.

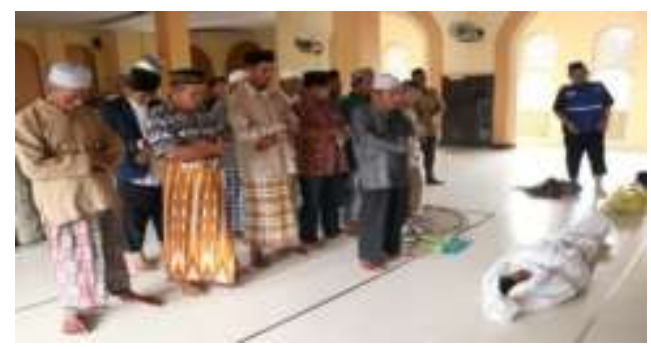

Gambar 1.2. Pelatihan Penyelenggaraan Jenazah (PPJ) 
Hasil Kegiatan menunjukkan bahwa gambaran masyarakat sebelum mengikuti seminar KKN STIBA Makassar ialah sebagian masyarakat telah mengetahui tata cara penyelenggaraan jenazah, namun, masih kurang tepat dalam pelaksanaannya. Setelah mengikuti kegiatan PPJ, masyarakat telah mengetahui banyak ihwal tata cara penyelenggaraan jenazah mulai dari proses memandikan jenazah, pemakaian kain kafan hingga mensolati jenazah. Tampak pula masyarakat memahami bagaimana

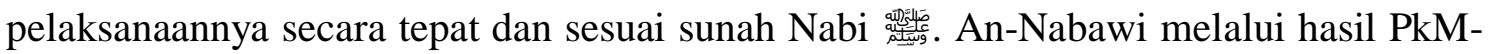
nya ihwal pelatihan penyelenggaraan jenazah menunjukkan bahwa Warga Gampong Paya Beurandang telah mampu mempraktekkan cara pengurusan jenazah secara baik dan benar sesuai dengan ketentuan syariat Islam. Masyarakat juga mampu mengurus jenazah yang mengidap penyakit menular secara baik sesuai dengan prinsip-prinsip keamanan dan kesehatan. Masyarakat juga telah mampu mengatasi fobia terhadap mayat, sehingga tidak merasa takut kalau mengurus jenazah. ${ }^{8}$

Dengan demikian, keberlanjutan program PPJ ini yaitu dengan memberikan usulan kepada Kepala Desa Baruga agar dibentuknya tim penyelenggara jenazah di setiap dusunnya agar masyarakat ke depannya tidak perlu lagi memanggil pengurus jenazah dari luar desa.

\section{Silaturahmi Akbar dan Pelayanan Kesehatan (SAPK)}

Silaturahmi akbar dirangkaikan dengan pelayanan kesehatan gratis (bekam dan check up kesehatan) merupakan salah satu program yang diagendakan sebagai bentuk mengeratkan ikatan ukhuwah Islamiyah serta sebagai pelayanan kesehatan kepada masyarakat. Kegiatan ini dimulai dari memberikan pemahaman tentang pentingnya menjalin dan menguatkan ukhuwah Islamiyah kemudian ditutup dengan pelayanan kesehatan berupa bekam dan cek kesehatan. Kegiatan ini dilaksanakan pada senin, 22 Februari 2020 pada pukul 14.00-17.00 di Masjid Miftahussala Samariga.

Langkah-langkah kegiatan SAPK diawali dengan membuat konsep kegiatan, kemudian menyelesaikan administrasi kegiatan (persuratan), melakukan sosialisasi, dan melaksanakan kegiatan. Pada saat kegiatan peserta menerima materi seputar pentingnya menjaga ukhuwah Islamiyah, sembari dirangkaian dengan pelayanan kesehatan gratis kepada masyarakat di teras Masjid Miftahussala Samariga.

Pengalaman menarik terlihat dari antusias masyarakat terhadap kegiatan silaturahmi akbar yang dirangkaikan dengan pelayanan kesehatan gratis. Masyarakat berbondong-bondong meminta agar dibekam dan dicek kesehatannya karena jarang sekali ada kegiatan pelayanan kesehatan yang dilaksanakan di Desa. Sebagian wargapun ada yang awalnya takut-takut. Namun setelah dijelaskan manfaat dan khasiat dari bekam ala sunah Nabi ian

\footnotetext{
${ }^{8}$ An-Nabawi, M. M. Pelatihan Keterampilan Penyelenggaraan Jenazah di Gampong Paya Beurandang Kecamatan Tanah Luas Kabupaten Aceh Utara. Prosiding Seminar Nasional Hasil Pengabdian, Vol. 1, No. 1, (2018): h.361-371.
} 
WAHATUL MUJTAMA': Jurnal Pengabdian Masyarakat

Vol. 1, No. 1 (2020) : Hal. 75-89

Website: https://journal.stiba.ac.id

faktor pendukung agenda SAPK ini yaitu warga sangat mengapresiasi dan pengurus masjid pun dengan hangat memberikan izin pemakaian Masjid Miftahussala Samariga sebagai tempat diadakannya SAPK dengan fasilitas yang memadai.

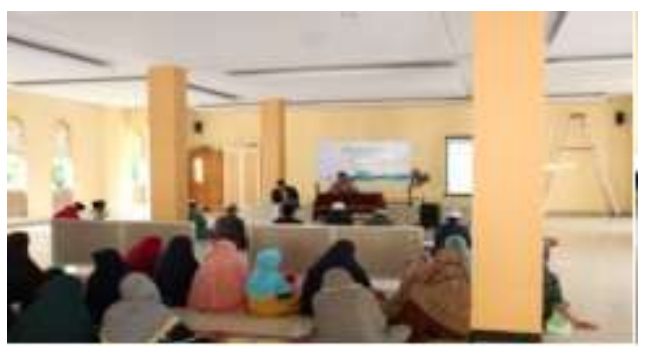

Gambar 1.3. Silaturahmi Akbar

Kendala yang dijumpai adalah kehadiran peserta dan kurang matangnya persiapan kegiatan. Dengan demikian, pelajaran yang dipetik dari kegiatan ini bagi mahasiswa KKN yaitu memaksimalkan undangan kepada masyarakat untuk menghadiri kegiatan serta mempersiapkan kegiatan sematang mungkin jauh-jauh hari sebelum SAPK dilaksanakan.

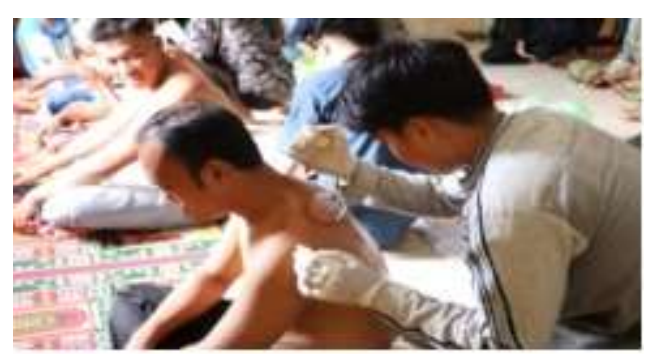

Gambar 1.4. Bekam Kesehatan

Hasil kegiatan sebelum masyarakat mengikuti SAPK tampak masyarakat belum mengetahui secara keseluruhan pengobatan Nabawi (Thibbun Nabawi) serta dan takuttakut untuk berbekam. Setelah mengikuti SAPK, masyarakat telah mengetahui salah satu pengobatan Nabawi yaitu berbekam sebagai alternatif dalam berobat serta tidak lagi takut untuk berbekam dan mengecekkan kesehatannya setiap bulannya. Hal tersebut ditengarai oleh proses internalisasi diri yang melekat pada masyarakat, sebagaimana faktor tertinggi yang mempengaruhi sikap masyarakat dalam metode penyembuhan alternatif bekam adalah faktor pribadi masyarakat berdasarkan hasil penelitian yang dilakukan oleh Kasmawati \& Muharram. ${ }^{9}$

Dengan demikian, keberlanjutan program kerja SAPK yaitu dengan membuka klinik bekam selama masa KKN dan menerima pelayanan bekam. Mengusulkan kepada

\footnotetext{
${ }^{9}$ Kasmawati, K., \& Muharram, S. Faktor-Faktor Yang Mempengaruhi Sikap Masyarakat Dalam Memilih Pengobatan Alternatif Bekam. Berkala Ilmiah Mahasiswa Ilmu Keperawatan Indonesia, Vol.7, No.1, (2019): h.19-30
} 
aparat desa untuk mengadakan pelatihan bekam bagi warga Desa Baruga. Terakhir, Mengusulkan pengobatan bekam ke Posyandu/Pustu sebagai pengobatan alternatif.

\section{Festival Anak Saleh (FAS)}

Kegiatan festival anak saleh merupakan puncak dari kegiatan pengajaran TK/TPA. FAS dimaksudkan untuk meningkatkan kepercayaan diri santri, menumbuhkembangkan minat dan bakat kesantrian anak-anak, serta meningkatkan daya kreasi, semangat berkompetisi dan spotifitas santri. Kegiatan ini dilaksanakan pada senin, 22 Februari 2020 pada pukul 14.00-17.00 di Masjid Miftahussala Samariga.

Langkah-langkah FAS dimulai dengan agenda membuat konsep kegiatan, dilanjutkan dengan menyelesaikan administrasi kegiatan dan persuatan, kemudian melakukan sosialisasi, dan kemudian melaksanakan kegiatan. Adapun bentuk kegiatan FAS yaitu perlombaan antar TPA yang dilaksanakan selama 3 hari. Terakhir, penutupan dirangkaikan dengan pemberian hadiah bagi pemenang.

Pengalaman menarik yang dijumpai yaitu antusiasme santri dan santriwati terhadap kegiatan FAS sebagai wadah pengembangan bakat dan keterampilan santri dan santriwati serta persaingan yang sportif dalam melaksanakan perlombaan. Dijumpai pula faktor pendukung penyelenggaraan FAS ialah warga dan santri/santriwati sangat mengapresiasi kegiatan dan pengurus masjid pun dengan ramah memberikan izin pemakaian Masjid Miftahussala Samariga sebagai tempat diadakannya FAS dengan fasilitas yang mumpuni.

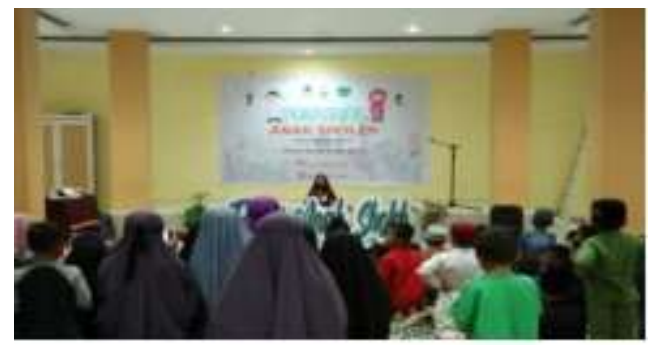

Gambar 1.5. Acara Festival Anak Saleh

Kendala yang ditemukan pada kegiatan FAS adalah kehadiran orang tua peserta kegiatan dan kurang matangnya persiapan kegiatan serta panitia yang kesulitan dalam mengurus santri dan santriwati saat proses kegiatan berlangsung. Pengalaman pembelajaran yang diperoleh adalah ke depannya kegiatan FAS diupayakan dengan memaksimalkan undangan kepada orang tua santri dan santriwati. Tujuannya untuk menghadiri kegiatan FAS dengan maksimal. Selain itu, mempersiapkan kegiatan sematang atau sesempurna mungkin serta memberikan arahan yang baik kepada santri dan santriwati agar tetap tertib dalam melaksanakan kegaitan.

Hasil kegiatan tampak masyarakat sebelum mengikuti FAS, dalam hal ini santri dan santriwati bosan dengan kegiatan TK/TPA dan kurangnya semangat dalam program TPA. Setelah acara FAS, santri dan santriwati lebih bersemangat mengikuti program 
TK/TPA sehingga kegiatan tersebut dapat dijadikan pemacu dalam belajar dan pengembangan diri. Hal serupa ditunjukkan oleh Fauzia, dkk., yang mengemukakan bahwa hasil dari program FAS di Dusun Jatibungkus tampak lebih bersemangat dalam mempelajari agama Islam, kemudian anak-anak Dusun Jatibungkus juga lebih berani untuk menunjukkan bakat serta rasa percaya dirinya makin meningkat setelah mengikuti program FAS. Hal tersebut dibuktikan dengan beberapa anak laki-laki di Dusun Jatibungkus yang semula tidak berani dalam melakukan adzan setelah dilakukannya pelatihan adzan dalam kegiatan FAS menjadi berani untuk melakukan adzan. ${ }^{10}$

Untuk keberlanjutan program diusulkan kepada pihak aparat pemerintah desa agar kiranya membuat kegiatan yang bernuansa Islami di setiap tahunnya di luar waktu KKN untuk meningkatkan dan mengembangkan kualitas santri.

\section{Rambu-Rambu Islami (RRI)}

Kegiatan RRI merupakan salah satu program kerja yang bertujuan sebagai syiar dakwah on the street. Rambu-Rambu Islami berupa sitatan wejangan, pengingat, dan dzikir yang mengajak kepada kemaslahatan dan menjauhi kemunkaran. Ihwal pemasangan RRI dilakukan di titik spot yang strategis dan telah disetujui oleh pemerintah Desa Baruga. Langkah-langkah RRI yaitu diawali dengan meminta perizinan pemasangan rambu-rambu Islami ke pihak pemerintah Desa Baruga, kemudian dirembuk-tentukan letak pemasangan rambu-rambu Islami tersebut. Selanjutnya, dipilah, dipilih, dan ditentukan konten/isi rambu-rambu Islami yang dinilai adaptif dan mudah dicerna-pahami oleh masyarakat. Setelah itu, dilakukan pemasangan rambu-rambu Islami di tempat yang telah disepakati oleh mahasiswa KKN dan pemerintah setempat.

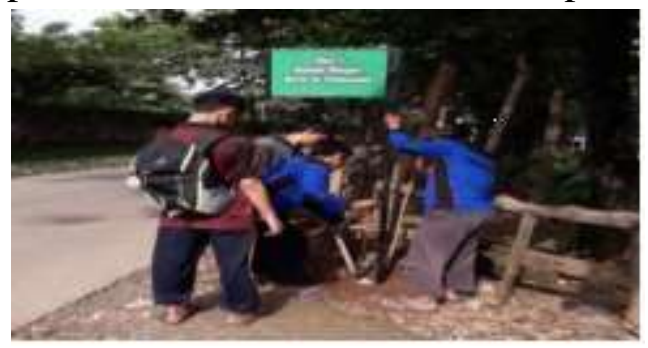

Gambar 1.6. Pemasangan Rambu-Rambu Islami

Pengalaman menarik yang dijumpai ialah terlihat beberapa masyarakat yang berkendaraan roda dua rela berhenti sejenak hanya untuk membaca tulisan yang terdapat pada rambu-rambu Islami yang telah ditancapkan di lokasi yang telah disepakati setelah pemasangannya dirampungkan. Hal itu barangkali merupakan berkah dikarenakan pemasangan Rambu-Rambu Islami telah mendapat dukungan penuh oleh pemerintah dan warga setempat.

${ }^{10}$ Fauzia, F., dkk. ARTIKEL dan Feature KKN UAD Divisi Xvii. A. 3" Penyelenggaraan Festival Anak Sholeh di Dusun Jatibungkus, Hargomulyo, Gedangsari, Gunungkidul, DIY". Festival Anak Sholeh, 2018. 
Kendala yang dihadapi selama menjalankan program RRI adalah pemetaan, waktu pemasangan yang kurang strategis dan kurangnya jumlah pengadaan Rambu-Rambu Islami. Hal ini kemudian dijadikan pelajaran pentingnya koordinasi yang baik dengan aparat pemerintah Desa Baruga dalam pemetaan atau peletakkan Rambu-Rambu Islami yang kurang strategis. Terlebih penyediaan atau pengalokasian dana dalam mempersiapkan Rambu-Rambu Islami agar lebih maksimal dalam pengadaannya.

Hasil kegiatan dijumpai masyarakat sebelum diadakannnya RRI yaitu kurangnya minat baca dalam keseharian (budaya literasi). Namun, diadakannya RRI, maka minat baca masyarakat menjadi bertambah. Hal itu dibuktikan dengan antusias warga dalam membaca rambu-rambu Islami yang telah diletakkan di lokasi-lokasi yang telah ditentukan. Adapun keberlanjutan program RRI, maka diusulkan kepada pihak pemerintah Desa Baruga untuk menyisipkan dana desanya (ADD) untuk pengadaan Rambu-Rambu Islami, serta mengajak masyarakat untuk saling menjaga salah satu aset dakwah desa yaitu Rambu-Rambu Islami.

\section{KESIMPULAN}

Kuliah Kerja Nyata (KKN) STIBA Makassar angkatan III adalah bertujuan untuk mengamalkan tri dharma perguruan tinggi sebagai wujud pengabdian kepada masyarakat. Bentuk-bentuk program kerja berupa Seminar Program Kerja (SPK), Pelatihan Penyelenggaraan Jenazah (PPJ), Silaturahmi Akbar dan Pelayanan Kesehatan (SAPK), Festival Anak Saleh (FAS) dan Rambu-Rambu Islami (RRI). Hasil dari KKN ini ialah dapat dilihat dari segi pengetahuan dalam masyarakat mengalami perkembangan wawasan keislaman, terutama dari sisi kemahiran mengenali huruf hijaiah, makraj dan tajwid dalam bacaan al-Qur'an. Dari segi keterampilan, terutama terlihat dari sisi kecakapan masyarakat dalam penyelenggaan jenazah. Dari segi sikap, masyarakat sudah memiliki antusiasme tinggi dalam mempelajari dan mengamalkan Ilmu Keislaman.

\section{DAFTAR PUSTAKA}

An-Nabawi, M. M. (2018). Pelatihan Keterampilan Penyelenggaraan Jenazah di Gampong Paya Beurandang Kecamatan Tanah Luas Kabupaten Aceh Utara. In Prosiding Seminar Nasional Hasil Pengabdian, Vol.1, No.1, h. 361-371.

Aslam, K., Mulia, I., Mahardika, H. D., Ariski, R., Istiqomah, N., Kholifah, A. N., ... \& Azka, F. M. (2019). Penguatan Keimanan dan Pengetahuan Masyarakat Dusun Bengkak dalam Rangka Program berkelanjutan KKN 220 Melalui Mini Perpustakaan dan Pemberian Buku Bacaan Islami. Prosiding Konferensi Pengabdian Masyarakat, 1, 33-36.

Asriati, N., \& Indrawati, U. S. Y. V. (2019). Pendampingan Program Usaha Mikro Kecil Menengah Berbasis Pusat Kegiatan Belajar Masyarakat (PKBM) Melalui KKN- 
WAHATUL MUJTAMA': Jurnal Pengabdian Masyarakat

Vol. 1, No. 1 (2020) : Hal. 75-89

Website: https://journal.stiba.ac.id

PPM Daerah Pemekaran Kubu Raya Kalimantan Barat. Jurnal Dinamika Pengabdian (JDP), Vol.5, No.1, h.12-18.

Fauzia, F., Hasanah, U., Irawati, D. A., Ramadhan, M. H., Wibisono, A. D., Rahman, T., \& Sepdiana, R. D. (2018). Artikel dan Feature KKN UAD Divisi Xvii. A. 3" Penyelenggaraan Festival Anak Sholeh di Dusun Jatibungkus, Hargomulyo, Gedangsari, Gunungkidul, DIY". festival anak sholeh.

Kasmawati, K., \& Muharram, S. (2019). Faktor-Faktor Yang Mempengaruhi Sikap Masyarakat dalam Memilih Pengobatan Alternatif Bekam. Berkala Ilmiah Mahasiswa Ilmu Keperawatan Indonesia, Vol.7, No.1, h:19-30.

Lingga, Z. A. (2019). Program KKN Tematik Citarum Harum Mahasiswa UPI 2018 dan Pembinaan Kesadaran Masyarakat Terhadap Lingkungan Hidup: Studi Deskriptif di Desa Cangkuang Kulon Kabupaten Bandung (Doctoral dissertation, Universitas Pendidikan Indonesia).

Mukit, A. (2019). Peningkatan Kesadaran Masyarakat untuk Membayar Pajak Melalui Program Sosialisasi Perpajakan (Studi pada Program Kerja KKN Mahasiswa IAIN Jember di Dusun Gambiran Desa Mumbulsari). Prosiding Konferensi Pengabdian Masyarakat, 1, 201-204.

Profil Desa Baruga tahun 2018.

Saharuddin, S. (2017). Pengabdian KKN-PPM Desa Wonorejo Kecamatan Mangkutana Kabupaten Luwu Timur. RESONA: Jurnal Ilmiah Pengabdian Masyarakat, 1(1).

Sari, N., Indarto, S. W., \& Wahyuningsih, S. (2014). Klasifikasi Sub Tipe Iklim Oldeman: Studi Kasus di Wilayah UPT.

Sulastri, A. (2017). Peran Program Kuliah Kerja Nyata Tematik Pos Pemberdayaan Keluarga (POSDAYA) Dalam Pengembangan Civic Participation Mahasiswa: Studi Deskriptif pada Pelaksanaan KKN Tematik Posdaya UPI di Desa Gunajaya Kecamatan Manonjaya (Doctoral dissertation, Universitas Pendidikan Indonesia). 